\title{
Pneumatocele in a Ugandan Female with SARS-CoV2 Infection: A Case Report
}

Sanjanaa Srikant ${ }^{1}$, Darshit Dave ${ }^{1}$, and Dhara Dave ${ }^{2}$

${ }^{1}$ Makerere University Faculty of Medicine

${ }^{2}$ Texas Tech University Health Sciences Center Department of Internal Medicine

December 2, 2021

\begin{abstract}
Pneumatocele may complicate the course of SARS-CoV2 infection. Our article exhibits the value of early radiological imaging for the timely diagnosis and management of COVID-19 and its complications. Conservative management is the mainstay of treatment of pneumatoceles however prompt surgical intervention is imperative for complicated pneumatoceles.
\end{abstract}

\section{Hosted file}

pneumatocele.docx available at https://authorea.com/users/449109/articles/547711pneumatocele-in-a-ugandan-female-with-sars-cov2-infection-a-case-report

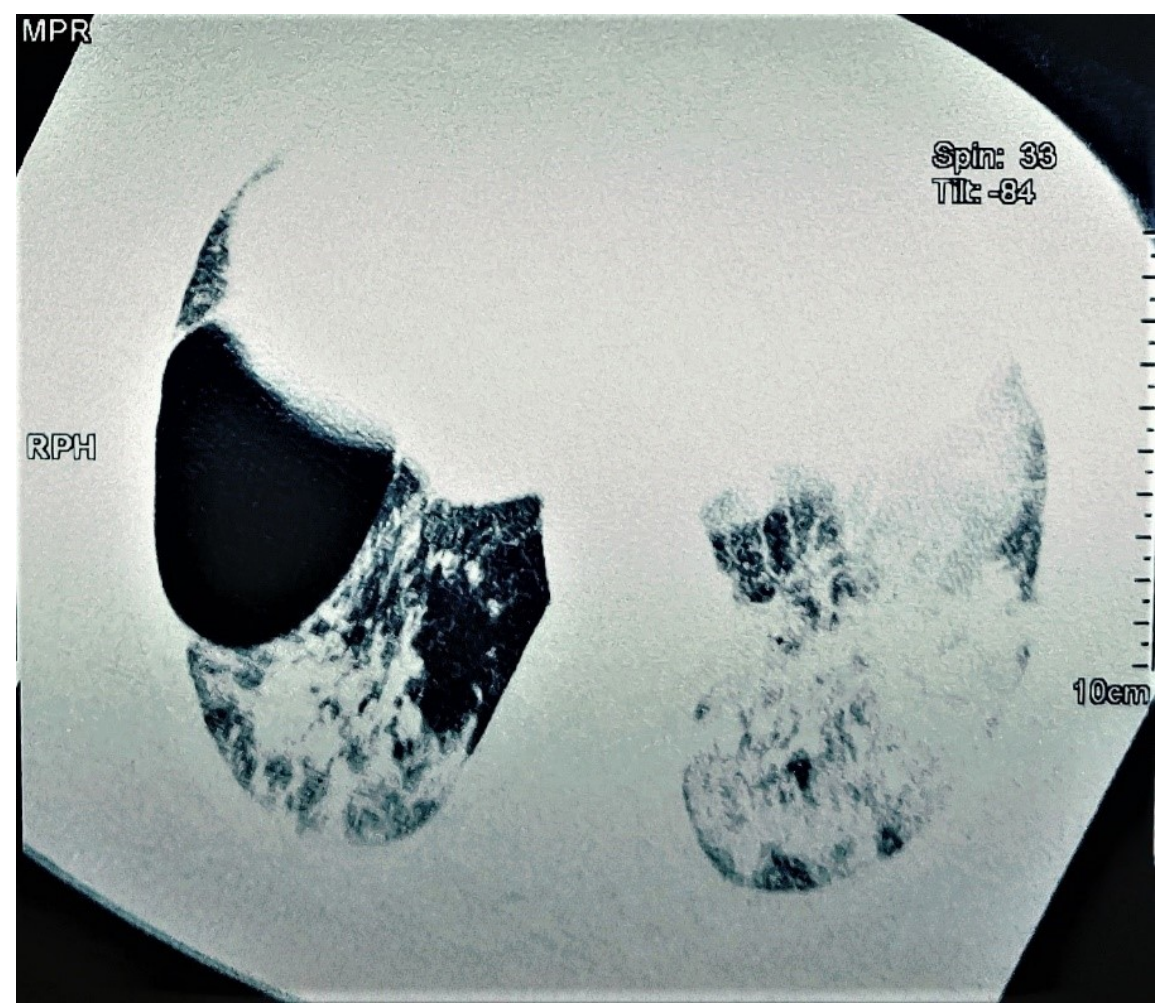




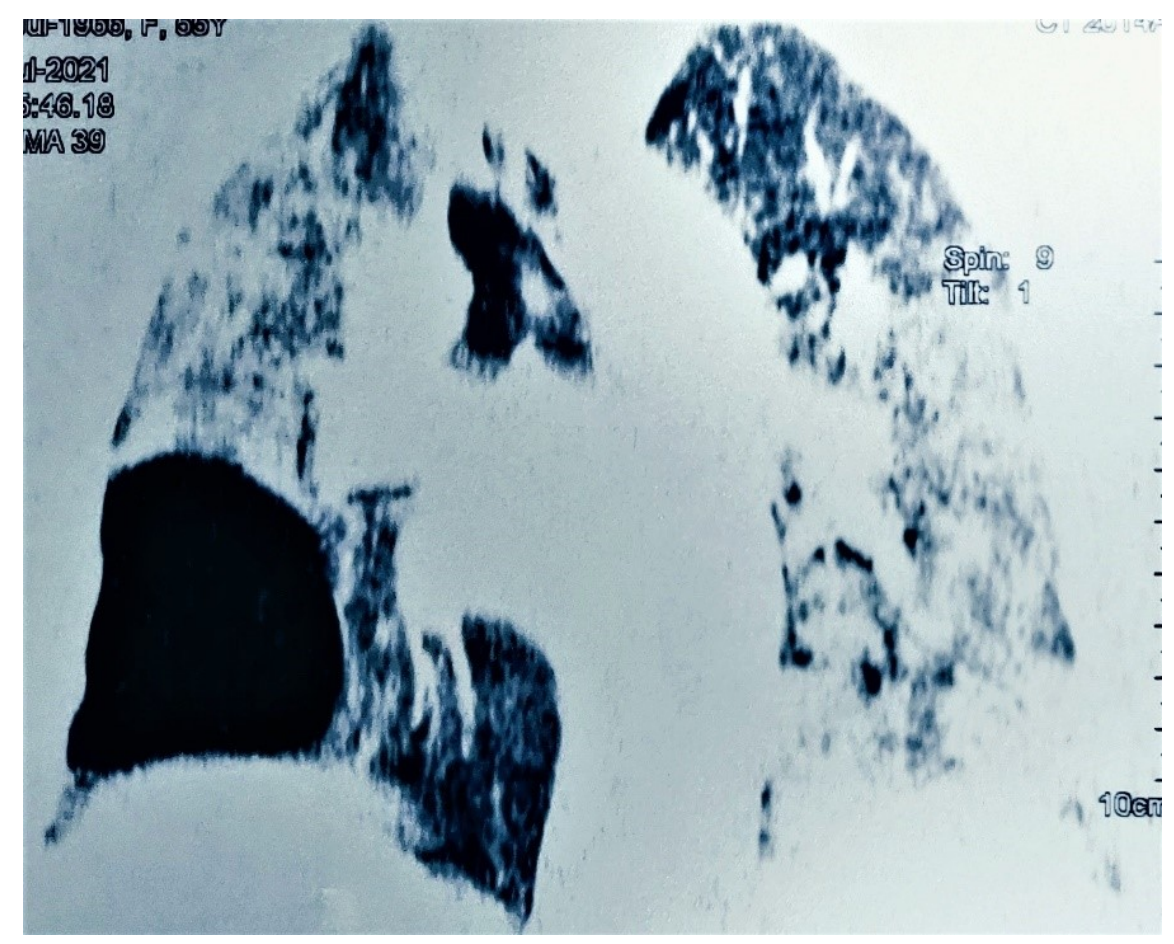

